\title{
The ability of habitual exercise to influence appetite and food intake in response to high- and low-energy preloads in man
}

\author{
S. J. Long, K. Hart and L. M. Morgan* \\ Centre for Nutrition and Food Safety, School of Biomedical and Life Sciences, University of Surrey, Guildford, \\ Surrey GU2 7XH, UK \\ (Received 31 July 2001 - Revised 5 December 2001 - Accepted 13 January 2002)
}

\begin{abstract}
The present study tested the hypothesis that habitual exercisers demonstrate an increased accuracy of regulation of food intake in compensation for previous dietary energy intake. Twentythree lean healthy male subjects were divided into two groups on the basis of their habitual exercise levels: non-exercisers (no exercise sessions/week, $n$ 9), and exercisers ( $>$ two exercise sessions of $40 \mathrm{~min}$ or more/week, $n$ 14). The appetite response to covert liquid preloads of high $(2513 \mathrm{~kJ})$ energy (HE) and low $(1008 \mathrm{~kJ})$ energy (LE) was investigated Sixty minutes after the preload subjects were offered an ab libitum buffet-style meal and energy intake (EI) was calculated. Subjective hunger and satiety were assessed throughout using self-rated visualanalogue scales. Buffet EI in non-exercisers was not significantly different following the LE or HE preloads (mean compensation $7 \%$ ), but the exercise group significantly reduced their energy intake following the HE, compared with the LE, preload (mean compensation $90 \%$; $P=0.0035$ ). A broadly similar pattern of response was observed for both moderate (two to three sessions/week, $n$ 7) and high exercisers ( $>$ four sessions/week, $n$ 7). There were no significant differences between hunger or satiety ratings following HE or LE preloads for either group. However non-exercisers scored significantly higher on their self-ratings of hunger at the start of the study, before preload consumption, compared with the exercisers $(P<0 \cdot 01)$. These findings demonstrate that habitual exercisers have an increased accuracy of short-term regulation of food intake in compensation for preload manipulation, and provide additional support for advocating regular exercise in the prevention of overweight and obesity.
\end{abstract}

Exercise: Appetite: Food intake: Satiety

The role of exercise in the prevention of positive energy balance and obesity is well-recognised (King, 1999; Moore, 2000). Increases in physical activity are strongly correlated to lower levels of obesity (Lean, 2000) and regular exercise has been related to the success of weight (Fogelholm et al. 2000) or fat-mass maintenance (Pasman et al. 1999) after a low-energy diet. However, the mechanisms by which exercise may act to beneficially affect energy balance are not clear. In terms of the relationship between energy deficit and energy intake per se, shortterm feeding studies using the manipulation of preload energy content to alter energy balance have demonstrated differences in hunger and subsequent food intake following high- and low-energy preloads (Pliner, 1973; Lawton et al. 1993; Green et al. 1994). Appetite responses are thus dependent to some extent upon previous energy intake and sensitive to energy deficits induced through differences in intake. However, in contrast, energy deficits induced through increases in exercise do not generally result in short-term increases in hunger ratings or in an elevated energy intake (King et al. 1997a; Blundell \& King, 1998), and athletes in situations that require sustained performance, such as the Tour de France cycle race, have to learn in respect to food intake in order to prevent negative energy balance (Westerterp-Plantenga, 1999); in addition, becoming sedentary does not down-regulate food intake (Murgatroyd et al. 1999). This uncoupling between energy intake and energy expenditure when energy expediture is manipulated by exercise has been reported to persist for several weeks in obese individuals (Woo et al. 1982a, b); it has also been reported to occur to a lesser extent when energy expenditure is manipulated by diet (Westerterp-Plantenga et al. 1999).

However, in contrast to the weak coupling between

Abbreviations: HE, high-energy; LE, low-energy; VAS, Visual analogue scales.

* Corresponding author: Dr L. M. Morgan, fax +44 1483 300374, email 1.morgan@surrey.ac.uk 
energy intake and expenditure in the short term, physically active individuals who habitually exercise, such as runners, have been shown to have suitably high-energy intakes (Maughan et al. 1989), suggesting a positive relationship between long-term physical activity and food intake for the maintenance of body weight. If athletes and other individuals habituated to higher levels of energy expenditure show better coupling of energy expenditure and energy intake, it is possible that the physical activity levels in the general population are also able to influence appetite responses. In our previous studies we have noted that subjects who regularly participate in recreational exercise appeared better able to compensate for differences in preload energy content than those who did not (Long, 2000). In addition, recent data showing good compensation for differences in energy intake following periods of exercise in male subjects who undertake regular exercise (nonathletes) (King et al. 1999) suggest that exercise may improve the sensitivity of the appetite control system to manipulations of energy intake. If exercise does improve the sensitivity of an individual in detecting differences in energy intake, regular physical activity would therefore be important for the regulation of body weight not only through increases in energy expenditure but also improved appetite regulation.

The present study therefore tested the hypothesis that habitual exercisers demonstrate an increased accuracy of regulation of food intake in compensation for previous dietary energy intake. Short-term appetite responses following high- and low-energy preloads were measured in individuals who undertook regular exercise compared with those who undertook no exercise. Compensation for preload energy manipulations in subsequent food intake was also investigated to determine whether habitual exercise levels affected the subjects' ability to detect differences in preload energy manipulations and adjust energy intake accordingly.

\section{Materials and methods}

\section{Subjects}

Twenty-three healthy male subjects (age range 18-40 years) of normal weight for height (mean BMI 23.7 (SD $2.8) \mathrm{kg} / \mathrm{m}^{2}$ ) were recruited on the basis of their habitual exercise levels. All volunteers were asked to complete the Dutch Eating Behaviour Questionnaire (Van Strien et al. 1986) during recruitment, and only those subjects with scores of $<3.5$ in any one section were recruited for participation in the study. Subjects were initially asked to rate their participation in exercise as one of three categories: one session or less per week (habitual non-exercisers), two to three sessions per week (habitual moderate exercisers) or four or more sessions per week (habitual high exercisers). One exercise session was defined as at least $40 \mathrm{~min}$ of moderate to high intensity activity. In addition, in-house activity diaries were completed on two separate occasions for $7 \mathrm{~d}$, in order to verify subjects' self-related exercise levels, and follow-up interviews given after completion of the study to check habitual exercise levels during the previous 3 months. Subjects were then assigned to the representative group. In only one subject was there any discrepancy between these methods of assessing exercise; in this subject selfreported exercise levels were taken, due to exceptional personal circumstances at the time of recording his activity diary.

Characteristics of each group are described in Table 1. Subjects showed no significant differences between groups in their Dutch Eating Behaviour Questionnaire scores or BMI. Before commencement of the study all volunteers were instructed that they must refrain from alcohol and exercise for the $24 \mathrm{~h}$ before each test occasion.

\section{Preloads and measurement of appetite}

Two preload meals were developed to provide high and low-energy through the manipulation of carbohydrate content. Each preload was given as a $450 \mathrm{ml}$ milk-shake consisting of double cream, maltodextrin and sucrose, and made up to volume with water. Vanilla essence $(1.5 \mathrm{ml})$ was added to each preload to improve palatability. The low-energy preload (LE) provided $1008 \mathrm{~kJ}$ and the highenergy preload (HE) provided $2513 \mathrm{~kJ}$ (Table 2).

Food intake after consumption of the preload was assessed using an ad libitum buffet test meal (Rogers, 1993) which enabled subjects to choose from a range of familiar foods, appropriate to the time of day. Subjects were asked to rank various buffet food items in order of preference. They were then offered their second and third choices of sandwich fillings and food types. The total energy available from the buffet ranged from $10751 \mathrm{~kJ}$ to $12611 \mathrm{~kJ}$ depending on subjects' preferences and the subsequent food items offered; the protein:fat:carbohydrate ratio was approximately 13:38:49\% energy. The number and range of food items presented to each subject was identical on each test occasion. The buffet food was weighed

Table 1. Characteristics of subjects assigned to different groups on the basis of their habitual exercise levels. Restraint, emotional and external scores calculated from the Dutch Eating Behaviour Questionnaire (Van Strien et al. 1986)

(Mean values and standard deviations)

\begin{tabular}{|c|c|c|c|c|c|c|c|c|c|c|}
\hline & \multicolumn{2}{|c|}{ Age (years) } & \multicolumn{2}{|c|}{ BMI $\left(\mathrm{kg} / \mathrm{m}^{2}\right)$} & \multicolumn{2}{|c|}{$\begin{array}{l}\text { Restraint } \\
\text { score }\end{array}$} & \multicolumn{2}{|c|}{$\begin{array}{l}\text { Emotional } \\
\text { score }\end{array}$} & \multicolumn{2}{|c|}{$\begin{array}{l}\text { External } \\
\text { score }\end{array}$} \\
\hline & Mean & SD & Mean & SD & Mean & SD & Mean & SD & Mean & SD \\
\hline Non-exercisers $(n 9)$ & $22 \cdot 2$ & $2 \cdot 1$ & $24 \cdot 3$ & $3 \cdot 0$ & 1.9 & 0.5 & $2 \cdot 1$ & 0.5 & $3 \cdot 1$ & 0.3 \\
\hline Moderate exercisers $(n 7)$ & $27 \cdot 1$ & $6 \cdot 8$ & $24 \cdot 1$ & 3.6 & $2 \cdot 1$ & 0.7 & $2 \cdot 3$ & 0.8 & 3.0 & 0.6 \\
\hline High exercisers $(n 7)$ & $22 \cdot 1$ & $2 \cdot 8$ & 22.5 & 1.5 & 2.0 & 0.3 & $2 \cdot 3$ & 0.6 & 3.4 & 0.4 \\
\hline
\end{tabular}


Table 2. Macronutrient composition of low- and high-energy preloads (per $450 \mathrm{ml}$ serving)

\begin{tabular}{lcrrrr}
\hline & \multicolumn{2}{c}{$\begin{array}{c}\text { Low-energy } \\
\text { preload }\end{array}$} & & \multicolumn{2}{c}{$\begin{array}{c}\text { High-energy } \\
\text { preloadt }\end{array}$} \\
\cline { 2 - 3 } \cline { 6 - 6 } & $\mathrm{kJ}$ & $\mathrm{g}$ & & $\mathrm{kJ}$ & $\mathrm{g}$ \\
\hline Carbohydrate & 167 & 10 & & 1672 & 100 \\
Fat & 828 & 22 & & 828 & 22 \\
Protein & 13 & 0.8 & & 13 & $0 \cdot 8$ \\
Total energy & 1008 & & & 2513 & \\
\hline
\end{tabular}

* Contained $46 \mathrm{~g}$ double cream and $10 \mathrm{~g}$ sucrose.

† Contained $46 \mathrm{~g}$ double cream, $10 \mathrm{~g}$ sucrose, $90 \mathrm{~g}$ maltodextrin.

before and re-weighed after each subject had finished eating, to allow calculation of energy and macronutrient intake. All dietary analyses were performed using Diet 5 for Windows (The Robert Gordon University, Aberdeen).

Subjective assessment of hunger and satiety was made using self-rating visual analogue scales (VAS) (Rogers, 1993). Each scale consisted of a $10 \mathrm{~cm}$ line anchored at either end with extreme statements; for example, the scale 'how hungry do you feel?' ranges from 'not at all hungry' to 'as hungry as I have ever felt'. Subjects were instructed to rate themselves by marking the scale at the point which was most appropriate to their feeling at that time. Ratings on the scales were converted to a score in centimetres for statistical analysis of the appetite responses to each treatment.

\section{Study protocol}

Using a randomised single-blind crossover design the appetite and food intake response to each preload was investigated. Subjects were instructed to consume their evening meal before midnight on the night before each study occasion, and to consume the same meal before the next study occasion.

On the morning of each study subjects were asked to consume their normal breakfast before 09.30 hours, and to consume the same breakfast on each test occasion. These were recorded in a diet diary. Following breakfast

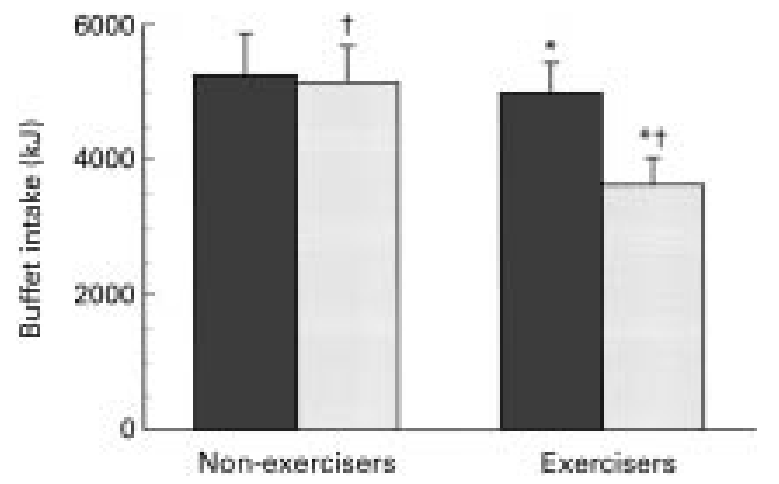

Fig. 1. Buffet test meal energy intake following either a low- ( $\square$ ) or a high-energy (国) preload in a group of habitual non-exercisers ( $n$ 9 ) or exercisers ( $n$ 14). Values are means and standard errors of the mean. Columns sharing the same symbol denote significant differences between groups: $\left.{ }^{\star} P<0.01, \dagger P<0.05\right)$. subjects were instructed to eat or drink nothing except water until arrival at the investigation unit at 11.15 hours. After arrival at the investigation unit subjects had a 15 min rest period, and were then asked to complete baseline VAS ratings. Subjects were then offered either the LE or HE preload and instructed to drink at a steady pace. A second VAS rating was completed after consumption of the preload. Further VAS ratings were then completed at $20 \mathrm{~min}$ intervals for the next $60 \mathrm{~min}$, after which time subjects were offered the ad libitum buffet test meal. Subjects were instructed to eat until comfortably full from this meal, and to prevent over-consumption due to freely available food, subjects were informed they may take away any food they did not want to eat at that time. Energy and macronutrient intakes were calculated from the test meal. Following the buffet test meal consumption subjects completed a final set of VAS ratings and were then free to resume their normal activities.

\section{Statistical analyses}

Differences in buffet test meal intake after the high and low-energy preloads were compared within each exercise group using a paired $t$ test (2-tailed). Differences in intake between exercise groups following individual preloads were compared using one-way ANOVA and any differences were localised using the Tukey post-hoc test. Data were tested for normality of distribution and equality of variance with the Komologov-Smirnoff test and Bartlett's test for equal variance respectively.

Differences between buffet test meal energy intakes between the high- and low-energy preloads were used to calculate the compensation within subject groups for the difference in preload energy ((difference in buffet test meal energy intake/difference in preload energy) $\times 100)$.

Hunger and satiety ratings between the high- and lowenergy preload within each exercise group were analysed using repeated measures ANCOVA. The baseline rating ( $-5 \mathrm{~min})$ was used as the covariate, with preload and time (10 to $60 \mathrm{~min}$ ) as the repeated measures factors. Ratings following the buffet test meal were analysed separately using a paired, 2-tailed $t$ test as they were no longer primarily responsive to preload manipulations. To assess differences in hunger and satiety between exercise groups the difference in ratings between the high- and low-energy preloads was calculated for each group. These differences were then analysed using ANCOVA, using the $-5 \mathrm{~min}$ value as the covariate. Exercise group was an independent variable with time (10 to $60 \mathrm{~min}$ ) as the repeated measures factor.

Results are expressed as mean and SEM unless otherwise stated. $P$ values of $<0.05$ were considered to be statistically significant. Statistical analyses were carried out using the software package Statistica for Windows (Statsoft, Tulsa, OK, USA).

\section{Results}

Ad libitum buffet test meal intake

The two exercise groups (habitual moderate and high 
exercise) were initially combined and compared with the habitual non-exercise group. Buffet intake for these groups is shown in Fig. 1. Buffet test meal energy intakes in the non-exercising group were not significantly different following the LE or HE preloads, but the exercise group significantly reduced their energy intake following the HE, compared with the LE, preload $(P=0.0035)$. Buffet energy intake was not significantly different between exercisers and non-exercisers following the LE preload, but following the HE preload the non-exercise group had significantly higher buffet energy intakes than the exercise group $(P=0.0274)$. When the exercise group was subdivided into moderate and high exercisers, a broadly similar pattern of response was seen for the two groups. Moderate exercisers showed a reduced buffet energy intake following the HE compared with the LE preload $(P=0 \cdot 046)$. This difference just failed to achieve statistical significance for the high-exercise group $(P=0 \cdot 057)$.

Buffet macronutrient intake in exercisers and non-exercisers following the high- and low-energy preloads is shown in Fig. 2. The ratios of macronutrients selected in the buffet were similar to those offered, and did not differ between the exercisers and non-exercisers. The non-exercise group demonstrated no changes in macronutrient intake following the two preload conditions, whereas the exercise group demonstrated significantly reduced intakes for all three macronutrients, carbohydrate $(P=0.47)$, fat $(P=0 \cdot 00063)$ and protein $(P=0.0128)$, following the HE compared with the LE preload. A similar pattern was observed for both exercise groups. Differences in macronutrient intake reached significance with respect to fat in the moderate-exercise group $(P=0.0234)$, and carbohydrate in the high exercise group $(P=0.0476)$.

Habitual non-exercisers were found to have a low level of energy compensation in the buffet test meal for differences in preload energy intake, at $7 \%$. However, habitual exercisers had a good level of compensation, at $90 \%$. Mean compensation levels for the moderate- and highexercise groups were $99 \%$ and $82 \%$ respectively.

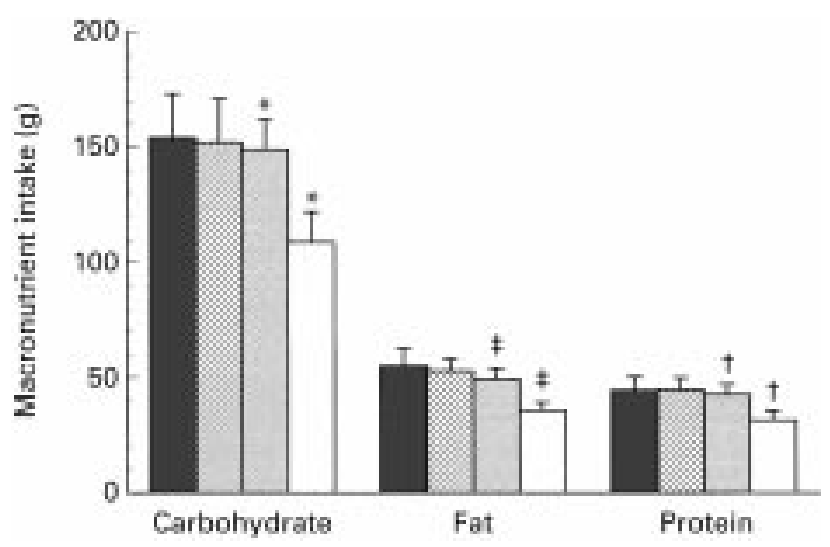

Fig. 2. Buffet test meal macronutrient intake following either a low$(\boldsymbol{\square}, \mathbf{D})$ or a high-energy $(\mathbb{Q}, \square)$ preload in a group of habitual nonexercisers $(\square, \mathbb{Q} ; n$ ) or exercisers $(\mathbf{Q}, \square ; n$ 14). Values are means and standard errors of the mean. Column sharing the same symbol denote significant differences between groups: ${ }^{\star} P<0.05$, $\dagger P<0.025, \ddagger P<0.01)$.

\section{Subjective assessment of hunger and satiety}

Self-assessed hunger and satiety ratings in exercisers and non-exercisers before and after the low- and high-energy preloads, and after the ad libitum buffet test meal, are shown in Tables 3 and 4. The non-exercise group scored significantly higher on their self-ratings of hunger at the start of the study, before preload consumption, compared with the exercise group $(P<0 \cdot 01)$, with both the LE and HE preload. However there were no significant differences between hunger or satiety ratings following the high- or low-energy preloads for either the habitual exercisers or non-exercisers. Hunger and satiety ratings following the buffet test meal were also similar between groups regardless of preload.

\section{Pre-study breakfast intake}

Breakfast energy intake was similar on each experimental occasion for both the exercise and non-exercise groups. There was no significant difference in breakfast energy intake (mean of the two occasions) between the habitual exercisers and non-exercisers (breakfast energy intake of habitual non-exercisers $v$. exercisers, 7570 (SD 2546) kJ v. 7354 (SD 2570) kJ, $P=0 \cdot 8$ ).

\section{Discussion}

Exercise has recently been shown to result in a good compensatory response to covert preload manipulation (King et al. 1999), suggesting that exercise may improve the sensitivity of the appetite control system in its response to previous dietary intake. We have previously undertaken studies in our laboratory using similar preloads and experimental design as the present study, in a group of subjects where exercise levels were not taken into account. Whilst the group as a whole showed a significant ability to distinguish between high- and low-energy preloads (Long, 2000), we observed that a few extremely sedentary individuals in the group were unable to compensate for preload energy. Data from the current investigation support a role for exercise in improving the ability of human subjects to compensate for differences in preload energy. Following consumption of high- or low-energy preloads, the habitual non-exercise group showed little compensatory response for the difference in preload energy in their subsequent food intake. Ad libitum buffet test meal intake was not significantly altered by manipulating preload energy content, with this group showing only a $7 \%$ compensation for differences in preload energy. In contrast, ad libitum buffet test meal intake in habitual exercisers was significantly smaller following the high-energy compared with the low-energy preload, and the exercise group as a whole achieved a $90 \%$ compensation for previous energy intake. When the exercise group was divided into moderate and high exercisers, this sensitivity to previous energy intake was apparent in both groups. It thus appears that relatively modest exercise (two to three sessions/week of moderate- or high-intensity activity) is sufficient to ensure accurate short-term compensation for previous energy intake. 
Table 3. Self-assessed hunger ratings at intervals before and after low-(LE) and high-energy (HE) preloads, and after ad libitum buffet test meal intake, in habitual non-exercisers $(n 9)$ and exercisers $(n 14)$

(Mean values and standard errors of the mean)

\begin{tabular}{|c|c|c|c|c|c|c|c|c|c|c|c|c|}
\hline & \multicolumn{12}{|c|}{ Hunger rating $(\mathrm{cm})$ at intervals after preload } \\
\hline & \multicolumn{2}{|c|}{$-10 \min$} & \multicolumn{2}{|c|}{$10 \mathrm{~min}$} & \multicolumn{2}{|c|}{$20 \mathrm{~min}$} & \multicolumn{2}{|c|}{$40 \mathrm{~min}$} & \multicolumn{2}{|c|}{$55 \mathrm{~min}$} & \multicolumn{2}{|c|}{ Post buffet } \\
\hline & Mean & SEM & Mean & SEM & Mean & SEM & Mean & SEM & Mean & SEM & Mean & SEM \\
\hline \multicolumn{13}{|l|}{ Non-exercisers } \\
\hline LE preload & $6 \cdot 15$ & 0.69 & 4.91 & 0.89 & 4.89 & 0.79 & $5 \cdot 68$ & 0.91 & 6.56 & 0.75 & 1.68 & 0.60 \\
\hline HE preload & 6.73 & 0.52 & 5.59 & 0.70 & 5.19 & 0.81 & 5.42 & 0.86 & 6.50 & 0.76 & 1.67 & 0.53 \\
\hline \multicolumn{13}{|l|}{ Exercisers } \\
\hline LE preload & 4.66 & 0.68 & $4 \cdot 26$ & 0.68 & 4.63 & 0.62 & 5.40 & 0.55 & $6 \cdot 34$ & 0.50 & 1.31 & 0.36 \\
\hline HE preload & 4.88 & 0.69 & 4.29 & 0.65 & 4.79 & 0.72 & 4.74 & 0.73 & 5.40 & 0.68 & $1 \cdot 16$ & 0.23 \\
\hline
\end{tabular}

Although the difference in compensation between moderate- and high-exercise groups was small, mean energy compensation was higher in the moderate than the high exercisers. This dissociation suggests that while food intake regulation may be improved at some levels of habitual exercise, dissociation in appetite responses could occur at higher exercise levels. This dissociation would support the observation of a discordance in energy intake and energy expenditure in very inactive and very active rats, with moderately active animals exhibiting a tight control between the two (Mayer et al. 1954).

Self-rated assessment of hunger and satiety followed the expected reciprocal relationship. There were, however, no significant differences in either hunger or satiety ratings between the low- and high-energy preloads in either the exercise or non-exercise group, suggesting that although food regulation was improved in subjects with higher habitual exercise levels, this was not directly related to differences in subjective feelings of hunger or satiety. It thus appears that differences in appetite control between the habitual exercisers and exercisers in the present study manifest themselves primarily as differences in intake. It is therefore possible that exercise increases sensitivity to satiety signals rather than hunger signals, and that food intake is more readily controlled through the cessation of an eating episode. Such a mechanism of appetite regulation would agree with previous work suggesting that obese subjects are less sensitive than lean subjects to short-term, post-ingestive satiety signals (Spiegel et al. 1989), and could help explain regular overconsumption in obese persons. Habitual exercisers scored significantly lower in their self-ratings of hunger at the start of the study, before preload consumption. The reason for this finding is unclear. Acute exercise, even at high intensity and/or duration has been found to have little sustained effect on subsequent hunger ratings (Imbeault et al. 1997; King et $a l$. $1997 a, b$ ). In view of the rapid drop-off rate for any exercise-induced anorexia that is seen (King et al. 1994), the ability of habitual exercise to influence hunger by 'stockpiling' these short-lived anorectic responses seems unlikely. Subjects were asked to consume their usual breakfast, giving rise to the possibility that differences in habitual breakfast energy intake could account for the initial differences in self-assessed hunger observed between the groups; however, pre-study breakfast energy intake was similar between the groups. This does not preclude the possibility of the initial differences occurring because of the choice of breakfast food; a wide range of different breakfast foods were habitually consumed by the subjects.

The mechanisms whereby habitual exercise might affect appetite remains to be established. However, one suggested mechanism whereby exercise may increase the accuracy of appetite regulation could be via effects of exercise on insulin sensitivity. Evidence to support an increase in insulin sensitivity in response to exercise is well-reported (Aldred et al. 1995; Poehlman et al. 2000), as is the evidence to implicate insulin sensitivity in the regulation of appetite (Haber et al. 1977; Holt et al. 1992). Measures of hunger and satiety have also previously been shown to

Table 4. Self-assessed satiety ratings at intervals before and after low-(LE) and high-energy (HE) preloads, and after ad libitum buffet test meal intake, in habitual non-exercisers $(n 9)$ and exercisers ( $n$ 14)

Satiety rating $(\mathrm{cm})$ at intervals after preload

\begin{tabular}{|c|c|c|c|c|c|c|c|c|c|c|c|c|}
\hline & \multicolumn{2}{|c|}{$-10 \min$} & \multicolumn{2}{|c|}{$10 \mathrm{~min}$} & \multicolumn{2}{|c|}{$20 \mathrm{~min}$} & \multicolumn{2}{|c|}{$40 \mathrm{~min}$} & \multicolumn{2}{|c|}{$55 \mathrm{~min}$} & \multicolumn{2}{|c|}{ Post buffet } \\
\hline & Mean & SEM & Mean & SEM & Mean & SEM & Mean & SEM & Mean & SEM & Mean & SEM \\
\hline \multicolumn{13}{|l|}{ Non-exercisers } \\
\hline LE preload & 3.63 & 0.74 & $5 \cdot 16$ & 0.86 & 4.79 & $0 \cdot 86$ & $2 \cdot 86$ & 0.34 & $3 \cdot 87$ & 0.66 & 6.49 & 1.02 \\
\hline HE preload & 3.07 & 0.66 & $5 \cdot 42$ & $0 \cdot 76$ & $4 \cdot 26$ & $0 \cdot 82$ & 4.49 & 0.77 & 4.46 & 0.90 & $4 \cdot 87$ & $1 \cdot 20$ \\
\hline \multicolumn{13}{|l|}{ Exercisers } \\
\hline LE preload & 3.69 & 0.73 & $4 \cdot 28$ & 0.73 & $4 \cdot 18$ & 0.64 & 3.83 & $0 \cdot 66$ & 3.02 & 0.49 & 8.01 & 0.36 \\
\hline HE preload & 3.46 & 0.61 & 4.63 & 0.73 & 4.51 & 0.73 & $4 \cdot 80$ & 0.70 & 4.43 & 0.70 & 8.00 & 0.50 \\
\hline
\end{tabular}


be closely related to changes in circulating glucose concentrations (Melanson et al. 1999), rates of glucose absorption (Kishnamacher \& Mickelsen, 1987), and hence insulin activity (Leathwood \& Pollet, 1988). Another potential mechanism could be modulation of gastrointestinal hormones which influence appetite. The gastrointestinal hormones cholecystokinin and glucagon-like peptide- 1 are both implicated in the short-term physiological control of appetite (Lieverse et al. 1995; Flint et al. 1998). Plasma cholecystokinin levels are raised following acute exercise in man (Bailey et al. 2001), whereas the effect of exercise on glucagon-like peptide-1 is unknown.

Our experimental protocol did not allow us to detect whether there was a difference in energy turnover between the exercisers and non-exercisers. The mean additional daily energy expenditure in the exercise group due to their exercise sessions was estimated from subjects' activity diaries at approximately $1500 \mathrm{~kJ} / \mathrm{d}$, some $15 \%$ of a typical $24 \mathrm{~h}$ energy expenditure of $10000 \mathrm{~kJ}$ (Frayn, 1996). It is therefore not unreasonable to suppose that daily energy expenditure might be higher in the exercise group.

Whilst the present study suggests an association between physical activity level and appetite regulation, it does not, however, show that exercise is a causal factor in enabling increasingly accurate compensation for previous energy intake. The role of lifestyle and cognitive differences between people who undertake regular exercise and those who do not must be considered, as this represents a large potential difference for feeding behaviour. Whilst the use of the Dutch Eating Behaviour Questionnaire in the current investigation enabled the subject groups to be balanced in terms of their dietary restraint, emotionality and externality, and covert preload manipulations were aimed to minimise the influence of external processes in the present investigation, the role of other beliefs and cognitive differences was not assesed. Future use of an intervention design whereby habitual non-exercisers are prescibed an exercise regimen, would enable the effect of exercise itself to be investigated.

The prevelence of obesity, with its attendent health risks, is steadily increasing in the UK (Fehily, 1999). Recent studies have classified some $29 \%$ of the population as sedentary; only $5 \%$ of women participate in regular vigorous physical activity (Fentem \& Walker, 1995). The present study demonstrates that habitual exercisers have an increased short-term accuracy of regulation of food intake in compensation for previous (preload) energy intake, and provides additional support for advocating regular exercise in the prevention of overweight and obesity.

\section{References}

Aldred HE, Hardman AE \& Taylor S (1995) Influence of 12 weeks of training by brisk walking on postprandial lipemia and insulinemia in sedentary middle-aged women. Metabolism 44, 390-397.

Bailey DM, Davies B, Castell LM, Newsholme EA \& Calam J (2001) Physical exercise and normobaric hypoxia: independent modulators of peripheral cholecystokinin metabolism in man. Journal of Applied Physiology 90, 105-113.

Blundell JE \& King NA (1998) Effects of exercise on appetite control: loose coupling between energy expenditure and energy intake. International Journal of Obesity 22, 522-529.

Fehily A (1999) Epidemiology of obesity in the UK. In Obesity. The Report of the British Nutrition Foundation Task Force, pp. 23-36. Oxford: Blackwell.

Fentem P \& Walker A (1995) Setting targets for England: Challenging, measurable and achievable. In Moving On: International Perspectives on Promoting Physical Activity, pp. 110-148 [AJ Killoran, P Fentem and C Casperson, editors]. London: Health Education Authority.

Flint A, Raben A, Astrup A \& Holst JJ (1998) Glucagon-like peptide-1 promotes satiety and suppresses energy intake in man. Journal of Clinical Investigation 101, 505-512.

Fogelholm M, Kukkonen-Harjula K, Nenonen A \& Pasanen M (2000) Effects of walking training on weight maintenance after a very-low-energy diet in premenopausal obese women: a randomized controlled trial. Archives of Internal Medicine 160, 2177-2184.

Frayn KN (1996) Metabolic Regulation - a Human Perspective. London: Portland Press.

Green SM, Burley VJ \& Blundell JE (1994) Effect of fat- and sucrose-containing foods on the size of eating episodes and energy intake in lean males: potential for causing overconsumption. European Journal of Clinical Nutrition 48, 547-555.

Haber GB, Heaton KW, Murphy D \& Burroughs LF (1977) Depletion and disruption of dietary fibre: effects on satiety, plasma glucose and serum insulin. Lancet ii, 679-682.

Holt S, Brand J, Soveny C \& Hansky J (1992) Relationship of satiety to postprandial glycaemic, insulin and cholecystokinin responses. Appetite 18, 129-141.

Imbeault P, Saint-Pierre S, Almeras N \& Tremblay A (1997) Acute effects of exercise on energy intake and feeding behaviour. British Journal of Nutrition 77, 511-521.

King NA (1999) What processes are involved in the appetite response to moderate increases in exercise-induced energy expenditure? Proceedings of the Nutrition Society 58, $107-113$

King NA, Appleton K, Rogers PJ \& Blundell JE (1999) Effects of sweetness and energy in drinks on food intake following exercise. Physiology and Behavior 66, 375-379.

King NA, Burley VJ \& Blundell JE (1994) Exercise-induced suppression of appetite: effects on food intake and implications for energy balance. European Journal of Clinical Nutrition 48, $715-724$

King NA, Lluch A, Stubbs RJ \& Blundell JE (1997a) High dose exercise does not increase hunger or energy intake in free living males. European Journal of Clinical Nutrition 51, 478-483.

King NA, Tremblay A \& Blundell JE (1997b) Effects of exercise on appetite control: implications for energy balance. Medicine and Science in Sports and Exercise 29, 1076-1089.

Kishnamacher S \& Mickelsen O (1987) The influence of different carbohydrate sources on blood glucose levels and satiety: effects of physical activity on blood glucose response. Human Nutrition 41F, 29-39.

Lawton CL, Burley VJ, Wales JK \& Blundell JE (1993) Dietary fat and appetite control in obese subjects: weak effects on satiation and satiety. International Journal of Obesity and Related Metabolic Disorders 17, 409-416.

Lean MEJ (2000) Is long-term weight loss possible? British Journal of Nutrition 83, S103-S111.

Leathwood P \& Pollet P (1988) Effects of slow release carbohydrates in the form of bean flakes on the evolution of hunger and satiety. Appetite 10, 1-11.

Lieverse RJ, Jansen JB, Masclee AA \& Lamers CB (1995) Satiety 
effects of a physiological dose of cholecystokinin in humans. Gut 36, 176-179.

Long SJ (2000) Investigation of the physiological mechanisms regulating appetite and food intake in humans. $\mathrm{PhD}$ Thesis, University of Surrey, May 2000.

Maughan RJ, Robertson JD \& Bruce AC (1989) Dietary energy and carbohydrate intakes of runners in relation to training load. Proceedings of the Nutrition Society 48, 170A.

Mayer J, Marshall NB, Vitale JJ, Christensen JH, Mashayekhi MB \& Stare FJ (1954) Exercise, food intake and body weights in normal rats and genetically obese adult mice. American Journal of Physiology 177, 544-548.

Melanson KJ, Westerterp-Plantenga MS, Saris WH, Smith FJ \& Campfield LA (1999) Blood glucose patterns and appetite in time-blinded humans: carbohydrate versus fat. American Journal of Physiology 277, R337-R345.

Moore MS (2000) Interactions between physical activity and diet in the regulation of body weight. Proceedings of the Nutrition Society 59, 193-198.

Murgatroyd PR, Goldberg GR, Leahy FE, Gilsenan MB \& Prentice AM (1999) Effects of inactivity and diet composition on human energy balance. International Journal of Obesity 23, 1269-1275.

Pasman WJ, Saris WH, Muls E, Vansant G \& WesterterpPlantenga MS (1999) Effect of exercise training on long-term weight maintenance in weight-reduced men. Metabolism: Clinical and Experimental 48, 15-21.

Pliner PL (1973) Effect of liquid and solid preloads on eating behavior of obese and normal persons. Physiology and Behavior 11, 285-290.
Poehlman ET, Dvorak RV, DeNino WF, Brochu M \& Ades PA (2000) Effects of resistance training and endurance training on insulin sensitivity in nonobese, young women: a controlled randomized trial. Journal of Clinical Endocrinology and Metabolism 85, 2463-2468.

Rogers PJ (1993) The experimental investigation of human eating behaviour. In Human Psychopharmacology, Measures and Methods, pp. 123-142 [I Hindmarch and PD Stonier, editors]. Chichester: John Wiley and Sons Ltd.

Spiegel TA, Shrager EE \& Stellar E (1989) Responses of lean and obese subjects to preloads, deprivation and palatability. Appetite 13, 45-69.

Van Strien T, Frijters J, Bergers G \& Defares P (1986) The Dutch Eating Behaviour Questionnaire (DEBQ) for assessment of restrained, emotional and external eating behaviour. International Journal of Eating Disorders 5, 295-315.

Westerterp-Plantenga MS (1999) Effects of extreme environments on food intake in human subjects. Proceedings of the Nutrition Society 58, 791-798.

Westerterp-Plantenga MS, Rolland V, Wilson SA \& Westerterp KR (1999) Satiety related to $24 \mathrm{~h}$ diet-induced thermogenesis during high protein/carbohydrate vs high fat diets measured in a respiration chamber. European Journal of Clinical Nutrition 53, 495-502.

Woo R, Garrow JS \& Pi-Sunyer FX (1982a) Effect of exercise on spontaneous calorie intake in obesity. American Journal of Clinical Nutrition 36, 470-477.

Woo R, Garrow JS \& Pi-Sunyer FX (1982b) Voluntary food intake during prolonged exercise in obese women. American Journal of Clinical Nutrition 36, 478-484. 